\title{
DAYTIME SLEEPINESS AND ACADEMIC PERFORMANCE IN MEDICAL STUDENTS
}

\author{
Raimundo Nonato D. Rodrigues', Carlos A.A. Viegas², Aída A.A. Abreu e Silva, Paulo Tavares ${ }^{4}$
}

\begin{abstract}
This report presents an analysis of the complaints of increasing daytime sleepiness as well as a study on their possible effects on the academic performance of medical students at the University of Brasilia. The Epworth Sleepiness Scale was applied to 172 medical students, at the beginning of August 1997 and at the end of November 1997. Academic performance was measured by analyzing the number of SS grades (from 9.0 to 10 over ten) and MM grades (from 5.0 to 6.9) attained in exams at the end of that school period. The results showed that at the beginning of the semester, 68 (39.53\%) of these 172 students already presented with excessive daytime sleepiness, and that of the 104 remaining students, 38 (22\%) developed daytime sleepiness by the end of the semester. Furthermore, it was observed that the sleepier students did not achieve as well as the others on their final examinations.
\end{abstract}

KEY WORDS: Epworth Sleepiness Scale, daytime sleepiness, medical students, academic performance.

\begin{abstract}
Sonolência diurna e desempenho acadêmico em estudantes de medicina
RESUMO - Este trabalho analisa a relação entre queixas de sonolência diurna crescente e desempenho acadêmico de estudantes de medicina da Universidade de Brasília. A escala de sonolência de Epworth foi aplicada em 172 estudantes de medicina no início de agosto de 1997 e no final de novembro (respectivamente início e final do semestre letivo). Estudou-se o desempenho acadêmico pela análise do número de menções SS (valores entre 9,0 e 10,0) e MM (valores entre 5,0 a 6,9) obtidas no final do referido semestre letivo. Os resultados revelam sonolência diurna desde o início do semestre em 68 alunos (39,53\%) e, nos 104 restantes, observou-se sonolência diurna crescente no decorrer do semestre em 38 alunos (22\%). Observou-se também que os estudantes mais sonolentos apresentaram pior desempenho acadêmico.
\end{abstract}

PALAVRAS-CHAVE: Escala de Sonolência de Epworth, sonolência diurna excessiva, estudantes de medicina, desempenho acadêmico.

The importance given to excessive daytime somnolence as a public health problem has increased lately, as it is one that affects almost $12 \%$ of all Americans ${ }^{1}$. Moreover, it has been held responsible for motor vehicle and work accidents, for difficulties in adapting to new situations, and for social maladjustment problems, as well as for a decrease in quality of life ${ }^{2-5}$.

The literature describes an excessive occurrence of daytime somnolence in occupations such as professional drivers ${ }^{6}$, workers who do night shifts ${ }^{7}$, and medical residents ${ }^{8}$ whose activities entail a lack of sleep as well as too much work, both of which cause stress.

Despite the importance of these facts, little is to be found in the literature regarding daytime excessive drowsiness in medical students, not to mention the academic consequences of this hypersomnolence.
This study, approved by the our University's Ethics Committee, aims to investigate the presence of excessive daytime somnolence in medical students and its possible consequences on their academic performance.

\section{METHOD}

A transversal descriptive study was carried out on the relationship between excessive daytime somnolence and academic performance among 300 medical students at the School of Medicine of the University of Brasilia (UnB), during the second semester of 1997. At UnB, medical students are distributed into groups by semesters, or periods, according to their semester of admission. Students from periods 1 to 10 were assessed, and those in the tenth semester were further separated into interns in Internal Medicine (10-a) and Surgery (10-b). Students in the seventh period were not included due to the fact that they were participating in another project.

Study developed at the Hospital Universitário Sleep Center, Universidade de Brasília (UnB), Brasília DF, Brazil: ${ }^{1} \mathrm{MD}$, MSc, Neurologist; ${ }^{2} \mathrm{MD}$, PhD, Pulmonologist; ${ }^{3} \mathrm{MD}$, General Practitioner; ${ }^{4} \mathrm{MD}$, PhD, Pulmonologist.

Received 17 July 2001, received in final form 12 September 2001. Accepted 29 September 2001. 
In order to assess daytime sleepiness, a questionnaire was elaborated based on the Epworth Sleepiness Scale $(\mathrm{ESS})^{9}$, translated from its original English version into Portuguese (Chart 1). When compared with the version used by other Brazilian authors ${ }^{10}$ no basic differences were found.

The ESS was initially applied during the first two weeks of August, 1997, when the second semester of that year was just beginning. This first inquiry was held during class hours, and only the students who were present at that moment were considered. The second ESS was applied during the last two weeks of November, 1997, when the semester was ending, using the same criteria as for the first sample. Both were carried out in randomly chosen classrooms, during the morning, in the middle of the week.

All ESS values were expressed as average plus or minus standard deviation ( $\mathrm{x} \pm \mathrm{sd}$ ), at the beginning and at the end of the semester, and then compared using the Student's t test. The differences between variables studied were considered statistically significant when $\mathrm{p}<0.05$.

In a second stage of the study, students were divided into 2 groups: Group 1 comprising students with ESS scores of up to ten, and Group 2 with ESS scores above ten, at the beginning of the semester.

We chose ten as the threshold because the literature on the subject ${ }^{11}$ refers to this score as the higher limit for normal controls, i.e. higher than that may be considered excessive daytime somnolence.

Chart 1. The Epworth Sleepiness Scale (ESS).

$\begin{array}{lccc} & & \begin{array}{c}\text { AVALIAÇÃO DE SONOLÊNCIA } \\ \text { (Epworth,1991) }\end{array} & \\ & & \text { Idade: } & \text { Data: } \\ \text { Nome: } & \text { Sexo: } & N^{\circ} \text { de matrícula: } & \end{array}$

Gostaríamos de saber qual a possibilidade do(a) senhor(a) cochilar ou mesmo dormir nas situações seguintes (não estamos falando de CANSAÇO e sim de SONOLÊNCIA !).Tais situações referem-se a seu modo de vida usual e em tempos recentes. Ainda que não tenha passado por uma destas situações ultimamente, tente imaginar como o (a) senhor(a) teria agido.

Use a seguinte escala para escolher o número mais apropriado para cada situação :

$0=$ NÃO COCHILARIA NUNCA.

$1=$ PEQUENA CHANCE DE COCHILAR.

$2=$ MODERADA CHANCE DE COCHILAR.

$3=$ GRANDE CHANCE DE COCHILAR.

SITUAÇÃO

CHANCE DE COCHILAR

1) Sentado, lendo.

2) Assistindo T.V.

3) Sentado e passivo em lugar público (teatro, reuniões, aulas, etc.)

4) Como passageiro numa viagem sem paradas, com duração de uma hora.

5) Deitado para descansar à tarde, quando as circunstâncias permitem.

6) Sentado, conversando com alguém.

7) Sentado tranqüilamente após um almoço, sem ingestão de bebida alcoólica.

8) No carro, enquanto parado por alguns minutos no tráfego. 
Considering Group 1 (students with ESS = 10 at the beginning of the semester), we watched for changes in their scores at the end of the semester. Thus, students were classified in three subgroups at the end of the semester. They were arbitrarily designated as:

G/DS - 25 students whose scores remained the same or decreased by the end of the semester.

$\mathrm{G}=10-41$ students whose scores rose but did not surpass ten.

G > 10 - 38 students whose scores rose to above ten.

Group 2 was excluded because the scores in this group were already greater than ten at the beginning of the semester. We did not take into consideration their academic achievement because we were interested in students who would develop excessive daytime somnolence during the semester.

At UnB, grades go from SS to SR, as follows: SS = superior (9 through 10, over 10 ); MS = superior average (7 through 8.9); $\mathrm{MM}=$ medium average (5 through 6.9); $\mathrm{MI}=$ insufficient average (3 through 4.9); II = insufficient (1 through 2.9); SR = no grade (0 through 0.9 ). The minimum passing grade is MM.

In order to measure the students' academic achievement, we analyzed the number of SS, MS, MM, and MI grades obtained in required subject matters by the three subgroups, G/DS, G > 10, and G $=10$.

The chi square test was used for comparative analysis of the distribution of grades between the different groups.

\section{RESULTS}

The answers to the questionnaires provided by the 172 students who were present both at the beginning and at the end of the semester were analyzed. These represented $55 \%$ of the original sample of 300 students.

Upon analysis of the data on the entire group of students, we observed that the overall ESS score average rose from $9.38( \pm 4.06)$ at the beginning of the semester to $10.72( \pm 4.03)$ at the end of the semester. This increase was found to be statistically significant $\left(p=0.02 \times 10^{-1}\right)$.

Following this observation, the group of 172 students was subdivided into Group 1 and Group 2, (with scores $=10$, and $>10$ at the beginning of the semester, respectively). Group 1 comprised 104 students $(60.46 \%)$. Group 2 comprised 68 students (39.5\%), who were considered as already displaying excessive daytime somnolence at the beginning of the semester. Among the 104 students of Group 1, the scores of 79 rose and those of 25 remained the same or diminished.

A comparative analysis revealed that the group of 79 students whose scores were equal or lower than ten at the beginning of the semester but rose
Table 1. Average of ESS scores of the $(n=104)$ students who started the semester with values $\leq 10$

\begin{tabular}{lccc}
\hline 'G & ESS & $\begin{array}{c}\text { Beginning } \\
\text { of semester }\end{array}$ & $\begin{array}{c}\text { End of } \\
\text { semester }\end{array}$ \\
\hline 38 & $>10$ & $7.68 \pm 1.93$ & $12.84 \pm 2.24^{(*)}$ \\
41 & $\leq 10$ & $5.29 \pm 1.96$ & $7.7 \pm 2.05^{(*)}$ \\
25 & decrease/same & $7.36 \pm 2.16$ & $5.88 \pm 2.27^{(*)}$ \\
\hline
\end{tabular}

$(*)=P<0.01$

ended up with an average score of $10.17 \pm 3.35$, while the group of 25 students whose initial scores were also $\leq 10$ but leveled off or fell by the end of the semester displayed a final average score of 5.88 \pm 2.27 . The difference between the two average scores was statistically significant $(p<0.01)$.

We then analyzed the group with 79 students, dividing it into the aforementioned subgroups $\mathrm{G}>10$, whose scores rose to above ten, and $\mathrm{G}=10$, whose scores rose but remained $\leq 10$. The observation of these two groups showed that G>10 displayed, at the beginning and at the end of the semester, average ESS scores of $7.68 \pm 1.93$ and $12.84 \pm 2.24$, respectively. The scores in group $\mathrm{G}=10$ were 5.29 \pm 1.96 and $7.70 \pm 2.05$, respectively. Both at the beginning and at the end of the semester, the difference between these two groups was significant $(p<00.1)$.

In Table 1, we can see the results obtained from the values that the ESS of the students who started the semester with values $\leq 10(\mathrm{G}>10, \mathrm{G}=10$ e G/ DS). At this point we began to study the possible consequences of excessive daytime somnolence on their academic performance, as measured by the students' grades. We only considered grades given in compulsory courses at the end of the second semester of 1997, as shown in Table 2.

If we compare these values, we can see that group G38 achieved fewer SS and more MM grades than group G/DS ( $21 \times 29$ and $62 \times 17 ; p=0.02 \times 10^{-1}$ and

Table 2. Students' grades by the end of the second semester of 1997 for the student groups G/DS, G>10 and $G=10$.

\begin{tabular}{lccc}
\hline & G>10 & G $=10$ & G/DS \\
\hline SS & 21 & 36 & 29 \\
MS & 79 & 106 & 57 \\
MM & 62 & 20 & 17 \\
MI & 1 & 3 & 1 \\
\hline
\end{tabular}


$p=0.01 \times 10^{-1}$, respectively). This means that the group with daytime sleepiness at the end of the semester ( $G>10)$ had worse academic results than the group without daytime sleepiness at the end of the semester (G/DS).

The ratios between grades other than SS and MM were not significant $(p<0.05)$ between these two groups.

Comparing grades between groups $\mathrm{G}=10$ and G/DS we can see that $p$ values were 0.25 for SS; 0.12 for MS; 0.32 for MM; and 0.57 for MI, i.e. there were no significant differences.

Finally, we compared the grades of the sleepy $(G>10)$ and intermediate $(G=10)$ students, and we observed higher grades in the second group, (SS, 21 $\times 36$ and MS, $79 \times 106$, with $p=0.03$ and $p=0.03 \times 10^{-1}$, respectively). G>10 got more MM grades ( $62 \times 20$, with $\left.p=0.01 \times 10^{-5}\right)$. This shows that $G>10$ had a worse academic performance than $G=10$. Similar results were found between the group without daytime sleepiness(G/DS) and the intermediate group $(G=10)$, when compared separately with the group with excessive daytime sleepiness ( $\mathrm{G}>10)$.

\section{DISCUSSION}

Somnolence is defined as the inability to maintain an adequate level of wakefulness, or as an excessive degree of daytime sleepiness ${ }^{10}$.

Reference to some of the consequences of excessive somnolence on medical activities may be found in the literature. Daugherty and Baldwin ${ }^{12}$ showed that too little sleep is debilitating and is harmful to the learning process, in a study based on answers to self-assessment surveys among students in the last two years of medical school and residents. Other studies on sleep deprivation in medical professionals $^{13,14}$ revealed a reduced capacity to perform intellectually demanding or non-stimulating tasks, especially among doctors with less professional experience. Another objective evaluation, carried out by Richardson et al. ${ }^{15}$ using the results of electroencephalograms of young residents during shifts, showed that this population suffers extreme sleep deprivation (less than 5 hours in bed; approximately 3.67 hours of actual sleep per night during shifts). It was also proved that sleep in a hospital does not restore from chronic sleep deprivation ${ }^{15}$.

Nonetheless, the consequences of sleep deprivation in doctors still constitutes a point of discussion among authors. Browne et al. ${ }^{16}$ found no significant changes in the capacity to learn and to retain new information, concluding that there were no nega- tive effects on the performance of his group of residents in surgery and medical students in internship in surgery who sleep only four hours a night.

In an interesting article, Green ${ }^{17}$ summarizes the results found in the literature on the effects of sleep deprivation on residents' performance, stating that well-rested residents surpass their colleagues who are under sleep deprivation in many cognitive tasks, such as memory, language and mathematical tests, the interpretation of electroencephalograms, anesthesia monitoring, information retention and problem solving, and visual attention, short-term memory and concentration tests. As to medical students, there is scarce information in the literature on the potential consequences of excessive daytime somnolence. Could this somnolence affect the grades or academic performance of the students? Could their individual behavior in response to the medical course be affected by it?

It is worthy of note that medical students are in a sort of strange limbo between academic life and real life, in a profession that should seek above all "not to cause more harm than the disease itself"18.

Johns ${ }^{11}$ pointed out that about $50 \%$ of these visibly normal and healthy young people find themselves needing to sleep during the day at least once a week. Any changes in their academic performance or evidence of somnolence during theoretic classes are usually only noticed by those in charge of their medical education or by the students' classmates.

One might also question whether the changes detected in the somnolence pattern as regards the academic performance of these youths could contribute to a discussion and, eventually, to a change in the curriculum of medical schools, or to recommendations on surveillance mechanisms aimed at detecting dangerous levels of somnolence.

We have yet less information regarding the causes of this excessive somnolence. There are countless possibilities, and factors may vary considerably ${ }^{19}$. We will not attempt to list them, as our goal is merely to study the relationship between excessive daytime somnolence and academic achievement. When we analyze our results, the first thing that draws our attention is the fact that $45 \%$ of the subjects participating at the beginning of the semester were not present when the ESS was taken at the end of the semester. This represents a high percentage of absenteeism. Apparently, these students had chosen to skip classes in order to study for their finals. Nevertheless we believe that the remaining $55 \%$ who 
answered the ESS on both occasions are totally representative of that particular population. Indeed, we were surprised to find such a high prevalence of daytime somnolence in the overall population of 172 students: $61.62 \%$ suffered somnolence at one point or another of the semester.

Based on this study, we were able to identify the changes in daytime somnolence of the students by the end of the semester. As mentioned in the description of the results, we divided the sample into three groups: G1, whose scores did not increase; G2, with scores that rose but did not surpass the threshold ESS value of 10; and G3, with scores that rose above the threshold. An analysis of the grades obtained by the students in each one of these groups showed that there was a significant degree of association $(p<0.05)$ between excessive somnolence throughout the semester and a smaller number of SS and greater number of MM grades. In other words, the academic performance of the students with excessive daytime somnolence was adversely affected. Another interesting observation was that Group G2, whose daytime somnolence did not rise above the threshold, displayed a behavior that was statistically similar to that of G1 (whose scores did not increase), suggesting that somnolence could really have an effect on grades.

The score of 10 points on the ESS proved in fact to be an excellent threshold for determining the presence of excessive somnolence as regards this group's performance, confirming the results of Johns ${ }^{11}$.

A literature review showed that there are many types of research that link daytime somnolence and professional performance ${ }^{4,8}$. In the field of Health it affects mainly those who look after chronic patients 9 , residents and young doctors ${ }^{14,16,20-22}$. Still, there have been remarkably few studies focusing on the influence of excessive daytime somnolence on medical students' academic output.

We found an interesting reference in literature ${ }^{10}$ that deals in part with this subject, in which the ESS scores of 616 medical students from the University of São Paulo Medical Faculty were followed up. In that study we find average ESS scores of $10.00 \pm$ 3.69 - statistically greater than those of Australian students $(7.60 \pm 3.90)$, according to Johns ${ }^{23}$. Comparing these results with ours, we can see that the average ESS scores of the medical students of the University of Brasilia at the beginning of the semester $(9.38 \pm 4.06)$, are lower than those of the Paulista (from São Paulo) students but higher than those of the Australian students. Still, the scores reached by the end of the semester $(10.72 \pm 4.03)$ were higher than both the Paulistas and the Australians. In the same study, one hundred and eleven of the original 616 students were tested at the beginning and at the end of 1995. They had an average score of 9.40 \pm 3.19 at the beginning of the year, and of $10.68 \pm$ 3.44 by the end of the year. This difference was significant $\left(p<0.01 \times 10^{-1}\right)$. In our study, the average ESS scores at the beginning and at the end of the semester were rather similar, from a phenomenological standpoint, to those of the Paulista group.

Ficke et al. ${ }^{24}$ analyzed the academic performance of 201 students - divided into snorers and non-snorers - as measured by their grades on the final Internal Medicine exams. His results showed that snorers only achieved average scores of $65 \%$ on their finals, while non-snorers achieved average scores of $71 \%$. The authors go further, stating that $26 \%$ of the snorers failed the exams, as opposed to only $13 \%$ of the non-snorers. Based on these facts they have established a relationship between snoring and excessive somnolence and, in an indirect manner, between daytime somnolence and low academic performance.

We would like to draw attention to the fact that a tired and sleepy medical student does not learn well, is often in a bad mood, and often becomes depressed (which makes the somnolence worse). This creates a terrible environment for learning, with high levels of stress and dwindling levels of motivation and of the ability to concentrate ${ }^{13,20}$. On the other hand, we deem it necessary to find alternative explanations for the great prevalence of daytime somnolence (61.62\%) among our supposedly healthy population.

In the first place, false information may be provided by students answering the ESS questionnaire. In addition, students may be unable to understand or may misinterpret the questions. Johns ${ }^{25}$ mentioned a certain group of individuals who constantly complained of daytime somnolence but nonetheless presented normal results upon objective measurements such as the TLMS. No satisfactory answer has been found for this fact. Furthermore, the ability to fall asleep easily at any time of day enjoyed by healthy young people does not mean that they have a problem with excessive daytime sleepiness ("High sleepability without sleepiness") ${ }^{26}$. Any of these factors may generate false results on the ESS.

Then as well, questions remain involving the definition of somnolence as measured by the test. 
Chervin et al. ${ }^{27}$ speculated that the neurophysiological state of somnolence may have different origins, symptoms and consequences.

In any case, these questions alone warrant the need to carry out further, more complete research on the subject. This will entail research on the parameters involved in the occurrence of daytime somnolence in a population such as the present one, as well as the creation of objective and quantitative methods for obtaining elucidative data on the relationship between sleep and academic performance.

Acknowledgements - To Miles Forrest, MD, for his assistance with the translation of this paper.

\section{REFERENCES}

1. Roth $\mathrm{T}$, Roehrs TA. Etiologies and sequelae of excessive daytime sleepiness. Clin Ther 1996;18:562-572.

2. Leger D. The cost of sleep-related accidents: a report for the National Commission on Sleep Disorders Research Sleep 1994;17:84-93.

3. Briones B, Adams N, Strauss C, et al. Relationship between sleepiness and general health status. Sleep 1996;9:583-588.

4. Lyznicki J, Doege TC, Davis RM, Williams MA. Sleepiness, driving and motor vehicle crashes. JAMA 1998;279:1908-1913.

5. Mitler MM, Dinges DF, Dement WC. Sleep medicine, public policy and public health In Kryger MH, Roth T, Dement WC (eds) Principles and practice of sleep medicine. 2.Ed. New York: Saunders, 1994:453-462.

6. McCarthy ME, Waters WF. Decreased attentional responsivity during sleep deprivation: orienting response latency, amplitude and habituation. Sleep 1997;20:115-123.

7. Bonnet M. Sleep deprivation. In Kryger MH, Roth T, Dement WC (eds). Principles and practice of sleep medicine. 2.Ed. New York: Saunders, 1994:50-67.

8. Johns M, Hocking B. Daytime sleepiness and sleep habits of Australian workers. Sleep 1997;20:844-849.

9. Bramwell L, MacKenzie J, Laschinger H, Cameron N. Need for overnight respite for primary caregivers of hospice clients. Cancer Nursing 1995;18:337-343.
10. Aloe F, Pedroso A, Tavares S. Epworth Sleepiness Scale outcome in 616 Brazilian medical students. Arq Neuropsiquiatr 1997;55:220-226.

11. Johns MW. A new method for measuring daytime sleepiness: the Epworth Sleepiness Scale. Sleep 1991;14:540-545.

12. Daugherty SR, Baldwin DC Jr. Sleep deprivation in senior medical students and first-year residents. Acad Med 1996;71:s93-s95.

13. Epstein R, Chiliag N, Lavie P. Starting times of school: effects on daytime functioning of fifth-grade children in Israel. Sleep 1998;21:250-256.

14. Light AI, Sun JH, McCool C, Thompson L, Heaton S, Bartle EJ. The effects of acute sleep deprivation on level of resident training. Curr Surg 1989;46:29-30

15. Richardson GS, Wyatt JK, Sullivan JP, et al. Objective assessment of sleep and alertness in medical house staff and the impact of protected time for sleep. Sleep 1996:19:718-726.

16. Browne BJ, Van Susteren T, Onsager DR, et al. Influence of sleep deprivation on learning among surgical house staff and medical students. Surgery 1994;115:604-610.

17. Green MJ. What (if anything) is wrong with residency overwork? Ann Intern Med 1996;124:932-933.

18. Nightingale F. Notes on Hospitals. London: Longman, 1863.

19. Levine B, Roehrs T, Zorick F, Roth T. Daytime sleepiness in young adults. Sleep 1988;11:39-46.

20. Baldwin PJ, Dodd M, Wrate RW. Young doctors' health: 1.How does working affect attitudes, health and performance? Soc Sci Med 1997;45:35-40.

21. Green MJ. What (if anything) is wrong with residency overwork? Ann Intern Med 1995;123:512-517.

22. Haynes DF, Schwedler M, Dyslin DC, Rice JC, Kerstein MD. Are postoperative complications related to resident sleep deprivation? South Med J 1995; 88:283-289.

23. Johns MW. Reliability and factor analysis of the Epworth Sleepiness Scale. Sleep 1992;15:376-381.

24. Ficke JH, Wiest GH, Hahn EG. Are snoring students more likely to fail their exams? Meeting Abstracts of the American Lung Association/ American Thoracic Society International Conference April 24-29, 1998.

25. Johns M. Sleepiness in different situations measured by the Epworth Sleepiness Scale. Sleep 1994;17:703-710.

26. Harrison H, Horne JA. "High sleepability without sleepiness": the ability to fall asleep rapidly without other signs of sleepiness. Neurophysiol Clin 1996;26:15-20.

27. Chervin RD, Aldrich MS. The Epworth Sleepiness Scale may not reflect objective measurements of sleepiness or sleep apnea. Neurology 1999;52:125-131 